\title{
Correction to: Tolerant semiaquatic bugs species (Heteroptera: Gerromorpha) are associated to pasture and conventional logging in the Eastern Amazon
}

\author{
Alana Patricia Meguy Guterres ${ }^{1,2}\left[\right.$. Erlane José Cunha ${ }^{1,3} \cdot$ Leandro Juen $^{1,2,3}$
}

Published online: 14 June 2021

๑) Springer Nature Switzerland AG 2021

\section{Correction to: Journal of Insect Conservation https://doi.org/10.1007/s10841-021-00316-9}

In the original publication, there was an error in stating that the RIL does not differ from the forest in the pattern of species distribution (abstract and conclusions). This is the only parameter in which these areas differ, as shown in the results and discussion.

Publisher's Note Springer Nature remains neutral with regard to jurisdictional claims in published maps and institutional affiliations.

The original article can be found online at https://doi.org/10.1007/ s10841-021-00316-9.

Alana Patricia Meguy Guterres

alanapatriciaapmg@gmail.com

1 Laboratório de Ecologia e Conservação, Instituto de Ciências Biológicas, Universidade Federal do Pará, Avenida Perimetral, ICB, Belém, PA 66075-110, Brazil

2 Programa de Pós-graduação em Ecologia Aquática e Pesca, Universidade Federal do Pará, Belém, PA, Brazil

3 Programa de Pós-graduação em Ecologia, Universidade Federal do Pará, Belém, PA, Brazil 